\title{
CHALLENGES AND OPTIMISM FOR SUSTAINABLE RESEARCH CAPACITY IN SIERRA LEONE
}

\author{
Emerson Abraham Jackson \\ Bank of Sierra Leone and (Distance Learning) Research Scholar in Sustainable Development at the University of Birmingham, e- \\ mail: emersonjackson69@gmail.com
}

\begin{abstract}
This article has provided a non-empirical approach in addressing the potential for sustainable research at all levels in Sierra Leone. It is an indisputable fact that remnants of the civil crisis and more lately, the Ebola crisis have contributed to the country' s under-developed research potential, more so at higher education level where the pace seemed to be slow in comparison to other countries in the West African sub-region. The country is making some strides in forging ahead with efforts being placed by individuals / institutions to improve opportunities for high level research in the country, but such a venture is faced with serious challenges. Highlights of some of the challenges include development of institutional capacity, strong strategic management capacity, and development in human capacity. Recommendations have also suggested attention focused on the building of strong institutional capacity and investment as the way forward in the sustained pathway of the country' s development.
\end{abstract}

KEYWORDS: Sustainability; Research capacity; Optimism; Challenge; Sierra Leone

\section{INTRODUCTION}

Research of all types, is the basis of sustained development and growth in an economic system; it nurtures the foundation for critical thinking, while at the same time, preparing the pathway for human epidemic quest for ontological inquiry. This requires intellectual prudence to discern the obvious good-will of a country's potential for sustained development; the most important aspect in the ontological journey, especially where living organisms are involved, is the manifestation of ethical prudence (addressed fully in latter part of this work).

As emphasised in Nuyens' (2005) book titled "No development without research - A challenge for capacity strengthening", there is an obvious attestation about the important role research plays in the development of human understanding and development of concepts, as applied in the health sector. Numerous disciplines and professional engagements can also attest to the relevance of research in improving human capacity, as revealed in the author's own research undertakings in areas pertaining to 'Action research in education' (Jackson, 2015), 'scholarly academic pursuance' (Jackson, 2016a and 2016b) and studies in 'economic methodology' (Jackson, 2016c).

The need for an improved reservoir of a knowledge society, through research is resounding all across the African continent and more so, emphatically in higher education institutions as exemplified in an excerpt work from Sawyerr (2004: 212): "The rise and spread of the knowledge society in the developed countries has led to the hegemony of modern knowledge and its manifestations and has opened up virtually all societies to increased pressure from global values, products, and services". There are potential benefits which generations can enjoy as a result of this endless task of human passion to explore knowledge, particularly in the developed economies where institutions (both academic and research-based) have worked concertedly to support the sustainability of structures and human existence.

Sawyerr's (ibid) view have alluded to the notion that, hegemony of knowledge concentration in the developed economies is a contributing factor to Africa's current state of political imbalance and also its high dependence on the importation of economic goods and services. In academic discourse, such allusive and unsubstantiated allegation can also serve as a starting point for critical debate, given the fact that many of those occupying influential positions in the (African) continent were once colleagues of political leaders in some of the developed and also, the newly industrialised economies.

In the journey of exploring optimism and challenges for research capacity in Sierra Leone, cognisance was given to the legacy of wreckages created by the ten year civil crisis in the late 1980 s to early 2000 s and more lately (early part of 2013 to mid-2015), the unexpected shock of the Ebola outbreak, which almost left the country void of knowledge and institutional collapse.

\section{BACKGROUND OF THE SIERRA LEONE ECONOMY AND RESEARCH POTENTIAL}

Sierra Leone has a history for delivering quality education, which incorporated classics (Latin and Greek), and eventually resulted in the country' s nomenclature, 'Athens of West Africa' (Jackson, 2016d and UNICEF, 2011). Affiliation of the then higher education institution (Fourah Bay College) with the University of Durham was very much needed in placing the country's education system and capacity for research at par $_{43}$ 
with institutions in the entire African continent.

The change of (school) curriculum in the early 1990s to reflect paradigm shift of new model of education and training in the West African sub-region, and coupled with the disaster of civil crisis and natural shock (Ebola) are largely to be blamed for the current low state of research capacity across the country's institutions, supposedly meant to nourish the potential for growth and development. The level of staff attrition experienced in higher education institutions during the late 1980s, and also the collapsed potential of resources in research-based institution is also an attestation of the current state of problems the country is experiencing, especially in nourishing capacity building.

Research is a dynamic endeavour and needs high level of investment, both in terms of human potential and infrastructural base to enable meaningful developments to be realised. There is need to strengthen the capacity base of the country's institutions, possibly continuous review of curricular systems and also investment in specialised areas of research training to support institutional needs, for example, enhancement in social sciences and scientific research and many more.

\section{APPROACHES TO RESEARCH INQUIRY AND CHALLENGES IN SIERRA LEONE}

Investment in research and backed by highly skills work force are the strong arm of a nation' s prospect for sustained development (ILO, 2012). Every country is making headway in this venture, be it in the area of pure scientific or social sciences endeavour. Research can take the form of qualitative or (and) quantitative approach and the capacity for this to happen depends on the level of structures that are made available in the system. Qualitative enquiry to start with, is mostly opened to professionals in the academia and techniques in this area can take the form of interviews (group or personalized), historiological analysis and many more. The capacity for this is in a country like Sierra Leone is quite a difficult task, as the capacity (both infrastructure and human potential) to promote such type of research is quite limited, both at university level and within specialised institutions of research in the country.

Despite the acclaimed non-scientific focus on qualitative techniques like grounded theory as criticised by a recent research output Pratt (2012), enhanced capacity for this in the country would be very worthwhile in ensuring that research is championed at the highest level. The scope to expand on knowledge acquisition through qualitative research endeavour is currently limited in the country. In this regard, there is a need to build research capacity on high level usage of qualitative techniques, and particularly as applied to usage of modern technologies like NVIVO and Atlas-ti in the analysis of qualitative research data.

Quantitative approach is also another common strand to research undertakings and in most cases, it usage is mostly pursued by researchers in the social sciences and pure scientific fields. Social scientists mostly rely on either 'secondary or primary data' usage, the latter pursued through the use of questionnaire surveys. The nature of knowledge enquiry in the social sciences discipline meant that, human interactions can be highly in use and outcomes of findings may vary from individual to individual, more so attributed to the psychological and economic state of mind of people. In the context of research work designed and pursued in developing economies like Sierra Leone, there is hardly any consideration given to ethical issues and their remedies (Jackson, forthcoming and Jackson, 2016b).

\section{INSTITUTIONAL CAPACITY}

Institutional capacity is very important in the coordination of high-level research exercises in an economic system. There are currently some established research-capacitated institutions in Sierra Leone, with potential of engineering high level research; these for example include the already established higher education institutions like University of Sierra Leone (incorporating Fourah Bay College, Institute of Public Administration and Management and College of Medicine and Allied Health Sciences), University of Makeni (currently hosting one of the most advanced technology system for Ebola research), the Bank of Sierra Leone (research department capable of promoting high level work in the area of macroeconomic and Central Banking studies), the Sierra Leone Agricultural Research Institute (SLARI) and many more.

The Macro-environmental conditions of public policy in relation to research priority of all types is fundamental to the journey of a country's research potential. In this vein, an effort to invest in high quality education is an integral part in the epistemological journey as emphasised in scholarly outputs across the African continent (Sawyerr, 2004). In the case with Sierra Leone, the deteriorating conditions in the quality of curriculum delivery, which to a great extent can be attributed to the legacy of the brutal civil crisis, which left the country almost void of quality researchers, can be blamed for the country's present problem. In this vein, research must be encouraged at all levels in the country's education system, and where possible, schools and more so, the public examination curriculum for university entrance should encourage independent research tasks similar to that of 'Extended Projects" offered to International Baccalaureate or A Level students in the UK. Such type of program will encourage learners to develop the underpinning skills needed for the development of independent and critical thinking skills.

Although efforts has been made to commence research-related postgraduate studies in some of the higher education institutions in Sierra Leone, there is still a long way to go in terms of ensuring standards are comparable to that of other countries in the West African sub-region, for example Ghana and Nigeria. The way forward on this, is to nurture tolerance in political and cultural discourses for citizens to address issues of concerns, particularly in the academia. This may also have the potential of creating an opportunity for research-based institutions to solicit internationally competitive funding to address areas of pertinent concerns in the country's pathway of sustained development through research undertakings.

\section{MANAGEMENT OF RESEARCH POTENTIAL AND CHALLENGES IN SIERRA LEONE}

The long history of civil unrest as already mentioned, is highly to be blamed for the current lagged state in the country's research capacity (Jackson, 2016e). Given the fact that the potential (incorporating infrastructural base and human resources) to further high level research work were more or less fractured during the civil crisis, is a serious concern for the country's opportunity to harness the potential of experienced and well exposed professionals both in the diaspora and the country at large.

In an excerpt from the South African Research and Innovation Management Association (SARIMA, n/d), it is confirmed that research based institutions, and appointed research and innovation managers in the 21 st century are operating within a44 
changed and challenging environment. In this situation, efforts must be directed at driving innovation in fulfilling multiple roles and responsibilities - where such roles and responsibilities, and also their associated challenged may include, but not only limited to some of the following:

1. Strategic Management - this is considered paramount in fostering research potential, aimed at the exploration of new found knowledge about concepts to be championed. In this regard, incentives must be focused in ensuring those engaged in research are given the necessary support to be innovative, while at the same time develop critical minds in addressing issues of global concern, for example the challenge of theories that may be contradictory to cultural boundaries. Accountability and inclusiveness are very important factor in the strategic management role of research-led institutions. Evidence from research have argued the fact that accountability and inclusiveness in governance by institutions are key determinants of economic performance (Casey et al, 2011); in fact, it is also confirmed that 'community driven development' (CDD) has the potential of ensuring that poverty efforts are sustainable and with immediate results outputted immediately (Dongier et al, 2003). A common challenge to this venture as in the case with a country like Sierra Leone is to do with funding, given the tightness of economic resources. Some innovative research ventures, particularly those in the natural sciences or modern technology-based sectors like Information and Communication Technology (ICT) require high-level infrastructural and human capacity to manage systems.

2. Contribution to economic and social development - as emphasised in the SARIMA (ibid) statement, there is an expectation that research endeavours and resource investments (in terms of time and finances) should be utilised to deliver some form of change or observed development to society. This in most occasions, is making possible for people to adapt to changes in their way of life, through cultural and social dynamism. Particularly in the social sciences, such innovative research initiatives and postmodern thinking involving thoughts around feminist and even trans-gender thinking, have the potential of provoking some form of cultural tension between traditional and post-modern thinkers. Despite its intrinsic challenge as already mentioned, openness in this area of innovative research ventures also have the potential of creating opportunities for the country's capacity to solicit international funding.

3. Monitoring, evaluation and quality assurance - this is very important, given the fact that taxpayers will need to be kept informed about the outcome(s) of their investment, especially in situations where public resources would have been heavily tied to research ventures. In this case, quality of outcomes would need to be monitored in terms of delivery and the impact of such investments to society. The main challenge to this is based on the fact that, some evaluative outcome on a project worth may be (positively) prejudiced on the basis of allegiance. To remedy such biased outcomes, it is advisable that independent watch-dog on all research ventures are used, which is similar to that of the 'Quality Assurance Agency (QAA) body set up for teaching and research ventures in the UK higher education system (QAA, 2014).

4. Sustainability of Human Resource Potential - this is very critical to the longevity of a country's potential to develop sustainable capacity for research potential. Lack of human potential capacity, particularly highly qualified and experienced personnel can pose serious threat to the sustained progress of institutional research in developing countries such as Sierra Leone. In a situation where funding is not sought as quickly as possible to help with the continued progress of institutional ventures and aspirations, institutions may be at risk of losing highly qualified personnel who may easily be unmotivated to stay.

\section{ETHICAL CONSIDERATIONS}

The application of either qualitative or quantitative research, and in some cases, combination of both normally referred to as 'Triangulation', is critically important to ensure ethical prudence is addressed, particularly as a way of adding credence to the profession. It is also an integral element in ensuring research participants are fully protected from the abuse of unscrupulous researchers / research-based institutions. The lack of consideration to unethical practices is not only common to research work carried out in a country like Sierra Leone, but also across many of the world's developing economies, probably due to the lack of institutional capacity needed to critically address common concerns. Such widespread problems / issues might be as a result of poor access to funding opportunities and also, the lack of strong guided principles of ethical code of practices as applied by research-based institutions in developed economies (CIS, n/d).

In order to protect the integrity of subjects / participants and also institutions, the use of European and US style institutional review board is considered a good way forward in adding credibility to the development of research potential in Sierra Leone. An excerpt from Morris and Morris (2016: 204) as seen in Figure 1, show the relevance of Institutional Review Board (IRB) in ensuring the ethics behind research is taken seriously by those intending to collect information from people or research subjects. Such body should incorporate personnel and components in ensuring that the key areas of concerns (Regulatory, Scientific and Ethics) are not overlooked in the process of granting access approval to research participants. This also provide strong base for value ethics to be exercised, for example, the situation whereby integrity and practical wisdom on human conscience can dictate the pace of what is considered to be good or bad; an approach rooted in Aristotolian philosophy (1886, translation). Although virtue ethics is criticize by some researchers (Hurka, 2001) as being too dictative in deciding on the outcome of the individual value judgment, it is however, a starting point for the manifestation of intellectual prudence.

Caution should be taken in order to ensure consistency is established amongst institution in the process of ethical reviews (particularly in the Medical and Social Sciences fields), as manifested in a recent research conducted by some UK professionals (Vadeboncoeur, 2016; Abbott and Grady, 2011 and Edwards et al., 2004). This is an attestation to show variances in the way ethical reviews are conducted, even as seem in the case with developed economies like the UK, where standards are said to be at the highest level.

\section{CONCLUSION AND REMEDY}

It is an obvious fact that authorities in Sierra Leone, particularly research-based institutions are very keen on improving the potential for high-level research in the country. Universities and other higher education institutions across the country are doing their best in reviewing curriculum to gain attention in attracting students, while at the same time ensuring international standards are achieved. Despite this, there is still a long way to go in 45 
getting the country to the level required in competing with similar economies in the West African sub-region.

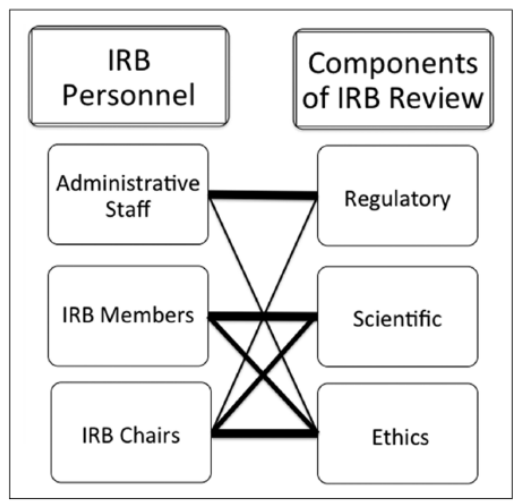

Research and investment provide the means for innovative thinking required by individuals and this also create scope for meaningful economic development in all sectors of an economy. As explained by Sawyerr (2014), where the right environment is created, there is the potential that investment in research can also bring about high level of contribution to the overall GDP contribution, while at the same time, fulfilling its underlying objectives of developing knowledge capacity and employment creation of citizens.

On this background, it is vital that attention is focused in terms of coordinating activities by all research-based institutions in the country to develop the enabling environment for researchers. The facilities at present to allow and promote good research are minimal and hence, discouraging retention of highly qualified personnel.

Going forward, lessons needs to be learned from a country like Ghana, which at some point in time, was in a worse situation than Sierra Leone, in terms collapsed institutional fabrics. Attracting highly qualified professionals from different backgrounds is the first step in mapping the country's journey towards sustained pathway of encouraging research potential. Institutions of higher education will also need to consider reviewing their curriculum to make sure research is incorporated at all levels of students' time of study. It is hoped that will help to develop the underlying capacity for already established research-based institutions to utilise the knowledge of new recruits, while advancing their potential into more specialist areas deemed necessary by institutions.

\section{REFERENCES}

1. Abbott L and Grady C (2011) A systematic review of the empirical literature evaluating IRBs: What we know and what we still need to learn. Journal of Empirical Research on Human Research Ethics, Vol. 6: pp. 3-19.

2. Aristotle (translated 1886) The Nicomachean Ethics of Aristotle (3rd edn). London: Kegan Paul, Trench \& Co.

3. Casey, K, Glennerster, R., and Miguel, E. (2011). Reshaping Institutions: Evidence on External Aid and Local Collective Action. National Bureau of Economic Research. Working Paper 17012. Available at: http://www.nber.org/papers/w1701. Accessed: 26th June 2017.

4. Council of International Schools [CIS]. (n/d). [Code of Ethics for Higher Education. Available at: https://www.cois.org/uploaded/Documentation/For_College s_and_Universities/Code_of_Ethics_for_Higher_Ēducation. pdf. Accessed: July 16, 2016.

5. Dongier, P., Van Domelen, J., Ostrom, E., Rizvi, A., Wakeman, W., Bebbington, A., Alkire, S., Esmail, T., and
Polski, M. (2003). Community-Driven Development. In "The Poverty Reduction Strategy Sourcebook", Vol. 1: pp. 301-331, Washington DC: The World Bank.

6. Edwards SJ, Ashcroft R and Kirchin S (2004) Research ethics committees: Differences and moral judgement. Bioethics, Vol. 18: pp. 408-427.

7. International Labour Office (ILI, 2012). A skilled Workforce for Strong, Sustainable and Balanced Growth. A G8 Training Strategy, ILO, Geneva. Available at: https://www.oecd.org/g20/summits/toronto/G20-SkillsStrategy.pdf. Accessed: $28^{\text {th }}$ June, 2017.

8. Jackson, E A. (2015). Impact of MOODLE platform on the pedagogy of students and staff: Cross-curricular comparison. Education and Information Technologies, Vol. 22(1): pp. 177 - 193. DOI: 10.1007/s10639-015-9438-9.

9. Jackson, E.A. (2016a). Ontological and Epistemological Discourse(s) on Sustainable Development: Perspective on Sierra Leone in the Aftermath of a Decade of Civil Unrest. Management of Sustainable Development, Vol. 8(1): pp. 35 $-43$.

10. Jackson, E.A. (2016b). Phronesis and the Epistemological Journey through Research undertakings involving Human Participants in the Context of Sierra Leone. Filosofia Theoretica: Journal of African Philosophicy, Culture and Religions, Vol. 5(2): pp. 35 - 53.

11. Jackson, E.A. (2016c). Economic Methodology: Paradox of Ceteris Paribus (CP) Law in the Context of Sierra Leone.

12. Jackson, E.A. (2016d). Proposal for Virtual ICT use in Sierra Leone Education System: A Case of MOODLE. Journal of Applied Thought, Vol. 5(1): pp. 79 - 94.

13. Jackson, E.A. (2016e). Competitiveness in Higher Education Practices in Sierra Leone: A model for Sustainable Growth. Economic Insights - Trends and Challenges, Vol. 4(4) pp. 15 - 25.

14. Jackson, E.A. (forthcoming). Critical Review of Sampling Procedures in the Context of Sierra Leone's Low Literacy (and Under-resourced) Research Communities

15. Morris, M.C., and Morris, J.Z. (2016). The Importance of Virtue Ethics in the IRB. Journal of Research Ethics, Vol. 12(4): pp. 201-216.

16. Nuyens, Y. (2005). No development without research - A challenge for capacity strengthening. Global Forum for Health Research, Geneva: Switzerland.

17. Pratt, J. (2012). The Problem of Grounded Theory. Centre for Institutional Studies, University of East London. Available http://roar.uel.ac.uk/1433/1/GroundedTheory.pdf. Accessed: $27^{\text {th }}$ June, 2017.

18. QAA. (2014). UK Quality Code for Higher Education - Part A: Setting and Monitoring Academic Standards. QAA, UK.

19. SOUTHERN AFRICAN RESEARCH \& INNOVATION MANAGEMENT ASSOCIATION (SARIMA, n/d). Leadership in Research \& Innovation Management. Available at: http://www.sarima.co.za/researchmanagement/. (Accessee: 2nd July, 2017).

20. Sawyerr, A. (2004). African Universities and the Challenge of Research Capacity Development. JHEA/RESA Vol. 2(1): pp. 211-240.

21. UNICEF (2011) The Role of Education in Peace Building: Case Study - Sierra Leone, UNICEF, New York. Voice of America (2014). Sierra Leone.

22. Vadeboncoeur, C., Townsend, N., Foster, C., and Sheehan, M. (2016). Variation in university research ethics review: Reflections following an inter-university study in England. Research Ethics, Vol. 12(4): pp. 217-233. 